\title{
The Relationship between Duration of Initial Alcohol Exposure and Persistence of Molecular Tolerance Is Markedly Nonlinear
}

\author{
Cristina Velázquez-Marrero, ${ }^{1 *}$ Patricia Wynne, ${ }^{2 *}$ Alexandra Bernardo, ${ }^{1}$ Stephanie Palacio,,${ }^{1}$ Gilles Martin, ${ }^{2}$ \\ and Steven N. Treistman ${ }^{1}$ \\ ${ }^{1}$ Institute of Neurobiology, University of Puerto Rico Medical Sciences Campus, San Juan, Puerto Rico 00901, and 2Brudnick Neuropsychiatric Research \\ Institute, University of Massachusetts Medical School, Worcester, Massachusetts 01604
}

\begin{abstract}
The neuronal calcium- and voltage-activated BK potassium channel is modulated by ethanol, and plays a role in behavioral tolerance in vertebrates and invertebrates. We examine the influence of temporal parameters of alcohol exposure on the characteristics of BK molecular tolerance in the ventral striatum, an important component of brain reward circuitry. BK channels in striatal neurons of C57BL/6J mice exhibited molecular tolerance whose duration was a function of exposure time. After $6 \mathrm{~h}$ exposure to $20 \mathrm{~mm}(0.09 \mathrm{mg} \%)$ ethanol, alcohol sensitivity was suppressed beyond $24 \mathrm{~h}$ after withdrawal, while after a 1 or $3 \mathrm{~h}$ exposure, sensitivity had significantly recovered after $4 \mathrm{~h}$. This temporally controlled transition to persistent molecular tolerance parallels changes in BK channel isoform profile. After withdrawal from $6 \mathrm{~h}$, but not $3 \mathrm{~h}$ alcohol exposure, mRNA levels of the alcohol-insensitive STREX (stress axis-regulated exon) splice variant were increased. Moreover, the biophysical properties of BK channels during withdrawal from $6 \mathrm{~h}$ exposure were altered, and match the properties of STREX channels exogenously expressed in HEK 293 cells. Our results suggest a temporally triggered shift in BK isoform identity. Once activated, the transition does not require the continued presence of alcohol. We next determined whether the results obtained using cultured striatal neurons could be observed in acutely dissociated striatal neurons, after alcohol administration in the living mouse. The results were in remarkable agreement with the striatal culture data, showing persistent molecular tolerance after injections producing $6 \mathrm{~h}$ of intoxication, but not after injections producing only $3 \mathrm{~h}$ of intoxication.
\end{abstract}

\section{Introduction}

The progression from recreational to compulsive alcohol use is influenced by many factors such as increased craving, loss of control, and acquired tolerance. Neural adaptations such as functional tolerance contribute to the development of alcoholism by either permitting or causing increased levels of alcohol consumption. These adaptations reduce the effects of alcohol, such that higher doses are required to maintain the same response. Importantly, longitudinal studies have shown that enhanced behavioral acute tolerance is one of the best predictors of future alcohol problems (Schuckit, 1994). Acquired alcohol tolerance and dependency have long been used as criteria for a diagnosis of alcoholism (Kalant, 1998).

Large conductance calcium-activated potassium (BK) channels may provide insights into the bridge between tolerance at the molecular and behavioral levels. BK has been shown to be a key

\footnotetext{
Received 0ct. 14, 2010; revised Nov. 17, 2010; accepted Dec. 16, 2010.

These studies were supported by funds from the National Institutes of Health, National Institute on Alcohol Abuse and Alcoholism. We thank Andrew Wilson for his support and technical advice. We also thank Jose Lemos and Andrew Tapper for helpful commentary throughout the course of this study. We are indebted to Roberto Melendez for sharing his expertise regarding intraperitoneal alcohol injection and subsequent blood alcohol levels in mice.

${ }^{*}$ C.V.-M. and P.W. contributed equally to the manuscript.

Correspondence should be addressed to Steven N. Treistman, Institute of Neurobiology, 201 Boulevard del Valle, San Juan, Puerto Rico 00901. E-mail: steven.treistman@upr.edu.

DOI:10.1523/JNEUROSCI.5429-10.2011

Copyright $\odot 2011$ the authors $\quad 0270-6474 / 11 / 312436-11 \$ 15.00 / 0$
}

component of behavioral tolerance to alcohol in invertebrates (Scholz et al., 2000; Ghezzi et al., 2004; Cowmeadow et al., 2005, 2006). In mammalian neurons, molecular tolerance of $B K$ to alcohol includes reduced sensitivity to the drug, which occurs within minutes, and a slower developing declustering and internalization, measured in hours (Pietrzykowski et al., 2004). Use of genetically altered mice in which the $\beta 4$ subunit of the BK channel is knocked out indicate that this subunit influences alcohol acute molecular tolerance at the single-channel and action potential levels, as well as influencing behavioral tolerance, and remarkably, the propensity of mice to drink alcohol. Thus, as in human studies, the presence of acute tolerance is a predictor of drinking behavior (Martin et al., 2008).

The transition from drug abuse to compulsive drug use is influenced by parameters of drug exposure (Ahmed and Koob, 1998), including concentration and temporal pattern (Lê and Kalant, 1992). For example, escalation of cocaine intake has been linked to drug exposure protocol in rats. Six hours appears to represent a critical time point, beyond which drug access leads to escalating drug intake (Ahmed and Koob, 1998). Here, we ask whether there are individual molecular transitions, selectively tripped by different temporal patterns of exposure, which influence the characteristics of BK molecular tolerance observed during withdrawal from alcohol. A number of reports in the literature describe changes in biochemical pathways involving, e.g., cyclic nucleotide and CREB alterations, or in the persistent 
activation of genes such as $\Delta$ FosB, that outlast the presence of the initiating drug of abuse, and so would qualify as drug-activated switches (Kelz et al., 1999; Nestler et al., 2001; Hyman et al., 2006; Renthal et al., 2008). In particular, we examine whether the transition observed in the persistence of alcohol molecular tolerance between 3 and $6 \mathrm{~h}$ of exposure might be related to a recently described mechanism whereby alcohol, via an epigenetic mechanism involving microRNA (miRNA), mediates a rapid reorganization of BK $\alpha$ isoforms (Pietrzykowski et al., 2008). Those isoforms that predominate after $6 \mathrm{~h}$ drug exposure are relatively resistant to alcohol's actions. Our results suggest that a process of isoform reorganization does, indeed, represent an important component of the transition to persistent molecular tolerance (PMT) observed between 3 and 6 h exposure times.

\section{Materials and Methods}

Primary striatal culture

Cultures of dissociated rat striatal neurons were prepared using a modification of a previously described protocol (Leveque et al., 2000). Briefly, postnatal day 8 Sprague Dawley rat pups were decapitated, and brains removed and immersed in ice-cold PBS. Next, the striatum was dissected out, transferred to HBSS (Invitrogen) with $10 \mathrm{~mm}$ HEPES, and dissociated using a fire-polished Pasteur pipette. Dissociated cells were transferred to the plating medium (a 1:1 mix of F12 nutrient mixture (Invitrogen) and DMEM medium supplemented with GlutaMAX; 2.0 mu glutamine final concentration), $2 \%$ fetal bovine serum (Hyclone), 2\% B-27 (Invitrogen), 1\% penicillin/streptomycin (Invitrogen). Cells in the plating medium were seeded onto $35 \mathrm{~mm}$ Petri dishes (Nunc) coated successively with $0.01 \%(\mathrm{w} / \mathrm{v})$ poly-L-ornithine (Sigma) and $33 \mu \mathrm{g} / \mathrm{ml}$ mouse laminin (Invitrogen). Twenty-four hours later, the medium was replaced with serum-free medium supplemented with $2 \%$ B-27, $2.0 \mathrm{~mm}$ glutamine and $1 \%$ penicillin/streptomycin. Thereafter, the medium was replaced every 3-4 d. Neuronal cultures were maintained in a $5 \% \mathrm{CO}_{2}$, humidified incubator $\left(99 \%\right.$ relative humidity) at $37^{\circ} \mathrm{C}$. All experiments were performed on neurons that were $14-21 \mathrm{~d}$ in culture.

For initial alcohol exposures, culture media was replaced with media containing $20 \mathrm{~mm}$ EtOH and incubated for 1, 3, or 6 h. For withdrawal periods, the dishes were washed 4 times with ethanol (EtOH)-free medium. Alcohol concentrations in the media at the end of the 1,3 , or $6 \mathrm{~h}$ exposure and after washing were measured using a GM7Analyser (Analox Instruments Inc.). Control dishes received media changes at the same time as the ethanol exposed dishes. Media changes did not have an effect on ethanol sensitivity of the channel. For electrophysiological experiments medium spiny neurons were identified by morphology (small to medium cell bodies and multiple thin processes) (Meredith et al., 1992).

\section{HEK cell transfection}

Cells from human embryonic kidney cell lines (HEK 293 cells) were cultured in DMEM medium supplemented with $10 \%$ heat-inactivated fetal bovine serum, $1 \%$ penicillin/streptomycin, and 25 mм HEPES (Invitrogen), and plated onto $25 \mathrm{~cm}^{2}$ flasks. The cells were maintained in a $5 \% \mathrm{CO}_{2}$, humidified incubator ( $99 \%$ relative humidity) at $37^{\circ} \mathrm{C}$. Before transfection HEK293 cells were split from confluent cultures and plated on $60 \mathrm{~mm}$ Petri dishes. For all experiments, $50-70 \%$ confluent cells were transfected using PolyFect transfection reagent (Qiagen) complexed with BK $\alpha$ variant (BK-Insertless, BK-ALCOREX, BK-STREX) and BK- $\beta 4$ subunit (when required) cDNAs in pVAX vector (Invitrogen) together with the expression plasmid ( $\pi \mathrm{H} 3-\mathrm{CD}-8$ ) encoding the $\alpha$ subunit of the human CD-8 lymphocyte surface antigen (GenBank M12824). To identify transfected cells, CD-8 antibody-coated beads were used (Dynal/ Invitrogen). Before electrophysiological recordings, $0.5 \mu \mathrm{l} / \mathrm{ml}$ of the CD-8 antibody-coated beads was added to each culture dish for $30 \mathrm{~min}$. Unattached beads were washed out with regular Locke's solution and recordings obtained from clearly identified cells with attached beads.

\section{Electrophysiological recordings}

Recording electrodes were pulled on a horizontal puller (Sutter Instruments), coated with Sylgard (Dow Corning), and fire-polished from borosilicate thin-wall capillary glass (Drummond) to a final resistance of 4-8 M $\Omega$. Currents were recorded in voltage-clamp mode with a HEKA EPC 10 amplifier at a sampling rate of $5 \mathrm{kHz}$ and $10 \mathrm{kHz}$ for whole-cell and single-channel recordings respectively, and low-pass filtered at 3 and $2 \mathrm{kHz}$, respectively. Leak currents were subtracted on-line using a conventional $\mathrm{P} / \mathrm{n}$ (4) protocol. In whole-cell mode, series resistance did not exceed $20 \mathrm{M} \Omega$ and was $60 \%$ compensated. Potentials and currents were digitized and stored using Patchmaster acquisition and analysis software version 2.05 (HEKA Elektronik).

Single-channel recordings. Conventional cell-attached patch-clamp mode was used, to maintain the intracellular milieu and secondary signaling pathways during recordings to assess ethanol sensitivity of single channels. Control (no alcohol) and ethanol-containing solutions were contained in $50 \mathrm{ml}$ syringes and expelled from hematocrit tubes. Each cell served as its own control. To determine baseline activity (defined here as open probability, $\mathrm{NP}_{\mathrm{o}}$ ) before alcohol application, $\mathrm{BK}$ channel activity was recorded 3 times, $20 \mathrm{~s}$ each, at $1 \mathrm{~min}$ intervals. For alcohol perfusion, the ethanol containing hematocrit tube was positioned close to the cell. Then, alcohol was applied and BK channel activity recorded in successive blocks of $20 \mathrm{~s}$ at $1 \mathrm{~min}$ intervals for up to $10 \mathrm{~min}$. Control experiments were performed in which patches were perfused with an ethanol-free solution for up to $15 \mathrm{~min}$. In control experiments, there was no significant deviation in baseline channel activity throughout the $15 \mathrm{~min}$ recording period (data not shown).

Cell-attached patch-clamp mode was also used to determine mean open/closed times. In these experiments, BK channel activity was recorded 3 times, $20 \mathrm{~s}$ each, with 1 min intervals. For all cell-attached experiments, the voltages given represent the potential at the intracellular side of the membrane.

To determine whether BK channels were present in the membrane of cultured striatal neurons we recorded single channels in the inside-out and outside-out patch-clamp configuration. We recorded in these configurations to precisely control the free intracellular calcium concentration to which BK channels were exposed. For all experiments, imposed voltages correspond to the potential at the intracellular side of the membrane. To measure the activation rate of channels in striatal culture, macroscopic currents were compiled by summing 100 consecutive single-channel traces obtained by stepping the membrane of an outsideout patch from a holding potential of $-60 \mathrm{mV}$ to a potential eliciting an $\mathrm{NP}_{\mathrm{o}}$ of $\sim 0.5$, between +30 and $+60 \mathrm{mV}$, in the presence of $10 \mu \mathrm{m}$ free $\mathrm{Ca}^{2+}$ (in the recording pipette). Leak currents were subtracted on-line using the $\mathrm{P} / \mathrm{n}$ (4) protocol. To yield the macroscopic current, traces were summed and the activation kinetics fit using Fitmaster software (HEKA Elektronik). The activation rate (milliseconds) versus voltage was plotted and linearly fit. The slope of the linear fit was used as the measure of voltage dependence.

Whole-cell recordings. Using the standard whole-cell patch-clamp recording method (Hamill et al., 1981), the membrane was depolarized to various potentials for $500 \mathrm{~ms}$ from a holding potential of $-60 \mathrm{mV}$. Mean BK current amplitude was measured at steady state, $450-490 \mathrm{~ms}$ after the beginning of the voltage step. The recording pipette routinely included in mM: 0.1 leupeptin, 12 phosphocreatine, $2 \mathrm{~K}$-ATP, and $0.2 \mathrm{Na}$-GTP to prevent run-down of the $\mathrm{Ca}^{2+}$ current (Kittler et al., 2005). The inclusion of leupeptin serves to block proteases while phosphocreatine and K-ATP allow the regeneration of ATP. When applying pharmacological agents such as 4-aminopyridine (4-AP), iberiotoxin (Ibtx), tetraethylammonium chloride (TEA-Cl), and 8-bromo-cAMP hemacrit tubes containing the appropriate solution were juxtaposed to the cell.

\section{In vivo ethanol exposure}

For these experiments, we used P25-P33 male C57BL/6J mice. Hourly $\mathrm{EtOH}$ intraperitoneal injections were administered. The first injection ( $1.8 \mathrm{~g} / \mathrm{kg}$, i.p.) was followed by booster injections $(1.2 \mathrm{~g} / \mathrm{kg}$, i.p.) every hour for two or five subsequent injections. BEC measurements were obtained from mice (naive, or immediately after a 3 or $6 \mathrm{~h} \mathrm{EtOH}$ injection protocol). Trunk blood was collected in heparinized capillary tubes, centrifuged $(1500 \times g$ for $5 \mathrm{~min})$ and analyzed using an alcohol oxidasebased assay. We measured blood alcohol levels on a GM7 MicroStat Analyzer (Analox Inst Ltd.). 
In vivo alcohol exposure and acute dissociation of striatal neurons Procedures for slice preparation and freshly isolated striatal neurons have been described in detail by Martin et al. (2008). Briefly, mouse brains (P25-P33) were sliced $(350 \mu \mathrm{m})$ using a Vibratome 3000 (Vibratome) and incubated for up to $6 \mathrm{~h}$ at room temp $\left(20-22^{\circ} \mathrm{C}\right)$ in a gassed $\left(95 \% \mathrm{O}_{2}\right.$ and $5 \% \mathrm{CO}_{2}$ ) saline solution. Following enzymatic digestion with protease XIV $(1 \mathrm{mg} / \mathrm{ml})$, the tissue was mechanically triturated using firepolished Pasteur pipettes, and cells were plated onto a $35 \mathrm{~mm}$ Petri dish.

\section{Neuron survival assay}

After rinsing the dissociated neurons with HBSS (Sigma-Aldrich), cells were stained with $7.5 \mu \mathrm{g} / \mathrm{ml}$ fluorescein diacetate and $2.3 \mu \mathrm{g} / \mathrm{ml}$ propidium iodide in HBSS. After $20 \mathrm{~min}$ at room temperature, the coverslips were mounted on slides and imaged immediately. With blue excitation, live neurons fluoresce green and dead cells fluoresce red (Brewer et al., 1993). The measure of survival was reported: percentage survival $=[$ live cells /(live cells + dead cells) $] \times 100$. In all acutely dissociated neuronal preparations, we observed $>84 \%$ viable neurons.

\section{Immunocytochemistry}

After acute dissociation, neurons plated on glass coverslips were fixed for 30 min with formaldehyde $3.7 \%$, permeabilized for 10 min with $0.1 \%$ Triton X-100 and blocked for 30 min with $10 \%$ goat serum in Dulbecco's PBS (DPBS) (Invitrogen) at room temperature. Samples were incubated overnight at $4^{\circ} \mathrm{C}$ with primary antibody, rabbit anti-glutamic acid decarboxylase 65/67 (GAD) (1:500; Sigma-Aldrich); followed by a $2 \mathrm{~h}$ incubation at room temperature with a secondary antibody mixture of Alexa Fluor 594 goat-anti-rabbit (1:300; Invitrogen) and mouse anti- $\alpha$ tubulin-Alexa 488 (1:300; Invitrogen). The nuclei of the cells were stained with $1 \mu \mathrm{g} / \mathrm{ml}$ Hoechst 33342 (Invitrogen) for $5 \mathrm{~min}$ at room temperature. Every treatment was followed by 2 PBS washes, $10 \mathrm{~min}$ each. The coverslips were mounted onto slides with Vectashield mounting medium (Vector Laboratories) and sealed with nail polish. Pictures were acquired through an LSM 5 Pascal Confocal Microscope (Zeiss) using a $40 \times$ oil-immersion objective. Immunostaining results indicate $83 \%$ of cells from the acutely dissociated preparation were markedly stained for GAD.

\section{Data analysis}

Data were analyzed using Tac X4.1.5 and TacFit X4.1.5 software (Bruxton). $\mathrm{NP}_{\mathrm{o}}$ values were calculated from all-points amplitude histograms by fitting the histogram with a sum of Gaussian functions using a Levenberg-Marquardt algorithm. Values for unitary current were obtained from the Gaussian fit of all-points amplitude histograms by measuring the distance between the modes corresponding to the closed state and the first opening level. The unitary conductance $(\gamma)$ was taken as the slope of the unitary current amplitude-voltage relationship. In single-channel patches, durations of open and closed times were measured with half-amplitude threshold analysis. A maximum-likelihood minimization routine was used to fit curves to the distribution of open and closed times. Determination of the minimum number of terms for adequate fit was established using a standard $F$ statistic table (significance level, $p<0.01$ ).

To compute $G / G_{\max }$, a series of macroscopic currents were obtained in the presence of $1 \mathrm{~mm} 4$-AP to block $I_{\mathrm{A}}$ current. Current traces were evoked from a holding potential of $-60 \mathrm{mV}$ to $+180 \mathrm{mV}$ or $360 \mathrm{mV}$ in 20 $\mathrm{mV}$ increments with 1 or $10 \mu \mathrm{M}$ free $\mathrm{Ca}^{2+}$ in the recording pipette, respectively. The conductance $(G)$ is the mean amplitude taken from the sustained portion of the macroscopic current, 450-490 ms after the beginning of the voltage step. $G_{\max }$ is the mean amplitude taken at the minimum voltage that elicits maximal current. Depolarizing steps greater than the minimum voltage do not elicit a significant amount of additional current.

\section{Experimental solutions}

Regular Locke's solution contained the following (in $\mathrm{mM}$ ): $2 \mathrm{KCl}, 142$ $\mathrm{NaCl}, 2 \mathrm{MgCl}_{2}, 2 \mathrm{CaCl}_{2}, 13$ glucose, and 15 HEPES. High potassium pipette solution contained the following (in $\mathrm{mm}$ ): 135-140 K-gluconate, 0-4 HEDTA [ $N$-(2-hydroxyethyl)ethylenediaminetriacetic acid], 0-4 EGTA, $15 \mathrm{HEPES}, 1 \mathrm{MgCl}_{2}$, and 0.5-2.2 $\mathrm{CaCl}_{2}$. HEDTA, EGTA, and
$\mathrm{CaCl}_{2}$ concentrations were adjusted to obtain the desired concentrations of free calcium, ranging from 1 to $10 \mu \mathrm{M}$ free $\mathrm{Ca}^{2+}$. Free $\mathrm{Ca}^{2+}$ concentrations were determined by Slider's software and confirmed with a Kwik-Tip calcium probe (World Precision Instruments).

\section{Chemicals}

Ethanol, HEPES, and $\mathrm{MgCl}_{2}$ were obtained from American Bioanalytical. $\mathrm{BaCl}_{2}$ and $\mathrm{CaCl}_{2}$ were from Fisher Scientific. Potassium gluconate, glucose, HEDTA, EGTA, TEA-Cl, 4-AP, Ibtx, 8-bromo-cAMP, leupeptin, phosphocreatine, KATP, and Na-GTP were obtained from SigmaAldrich. $\mathrm{NaCl}$ and $\mathrm{KCl}$ were from EM Science.

\section{Reverse transcription PCR}

Total RNA was isolated from the striatal culture dishes with TRIzol (Invitrogen). Manufacturer's instructions were followed for RNA isolation using an RNeasy Protect Mini extraction kit (Qiagen) and Glycol Blue (Ambion) to aid in the visualization of RNA precipitate. RNA quality (A260/280) and concentration was determined by a ND-1000 Spectrophotometer (NanoDrop). After extraction, total RNA aliquots were treated with $20 \mathrm{U}$ of RQ1 RNase-Free DNase (Promega) for $15 \mathrm{~min}$ at $37^{\circ} \mathrm{C}$ to minimize the risk of genomic DNA contamination. First strand cDNA was reverse transcribed from the DNase-treated aliquots using the iScript cDNA Synthesis Kit (Bio-Rad) and stored at $-20^{\circ} \mathrm{C}$.

A 6-carboxy-fluorescein reporter dye-based real-time PCR was used to quantify expression changes of BK $\beta 1$ and STREX (stress axis-regulated exon) mRNA in treated striatal cultures compared with control cultures and performed in triplicate. $\beta$-actin mRNA is unaffected by acute and chronic alcohol exposure in neuronal tissue and was used as an endogenous control to accurately calculate mRNA expression. No-reverse transcriptase and no-template controls were routinely included. The following pairs of primers were used: KCNMB1, ATCAAGGACCAGGAAGAGCTG ( $5^{\prime}$ primer) and CTACTTCTGAGCTGCCAAGAC (3' primer); and STREX AGGCGGCCCCAAGATGT ( $5^{\prime}$ primer) and ATGCACGAGCAGTCACGCTCA ( $3^{\prime}$ primer). All amplicons (the primers and probes) were checked for lack of secondary structure formation ensuring optimal PCR efficiency (IDT BioTools). Probes were synthesized to have their $5^{\prime}$ end labeled in $25 \mu$ l final volume, using Real Time Master Mix Probe (Eppendorf), on an ABI Prism 7500 PCR System (Applied Biosystems). The reverse-transcription reactions were performed at $42^{\circ} \mathrm{C}$ for $45 \mathrm{~min}$, followed by 35 cycles of PCR amplification $\left(15 \mathrm{~s}\right.$ at $94^{\circ} \mathrm{C}, 30 \mathrm{~s}$ at $56^{\circ} \mathrm{C}, 15 \mathrm{~s}$ at $72^{\circ} \mathrm{C}$ ). To verify that the signals detected were not caused by genomic DNA contamination, Reverse transcription PCRs were also performed for each pair of primers without reverse transcriptase. Significance was determined using one-way ANOVA.

\section{Results}

\section{Cultured striatal neurons express functional BK channels}

We first determined the basic electrophysiological properties, including voltage sensitivity and conductance, of single BK channels recorded from inside-out patches pulled from cultured striatal neurons (Fig. 1A). Single-channel currents were elicited by depolarizing the membrane from $-80 \mathrm{mV}$ to $+80 \mathrm{mV}$ in $20 \mathrm{mV}$ increments, while exposing the intracellular surface to $10 \mu \mathrm{M}$ free $\mathrm{Ca}^{2+}$. Singlechannel activity between $-60 \mathrm{mV}$ and $+40 \mathrm{mV}$ is shown in Figure $1 B$. At $-60 \mathrm{mV}$, the channel displays a low open probability $\left(\mathrm{NP}_{\mathrm{o}}=\right.$ $0.10)$, and shows increasing activity $\left(\mathrm{NP}_{\mathrm{o}}=0.96\right)$ as the membrane is depolarized to $+40 \mathrm{mV}$. Figure $1 C$ shows a plot of the current amplitude versus the membrane potential of a striatal BK channel. The current-voltage relationship is well fitted by linear regression $(r=0.99)$ yielding a slope conductance of $230 \mathrm{pS}$, similar to BK channels recorded in other preparations (McManus, 1991; Vergara et al., 1998, 1999). In addition, current reversed at $0 \mathrm{mV}$ in symmetric potassium conditions, $[\mathrm{K}]_{\mathrm{i}}=[\mathrm{K}]_{\mathrm{o}}$, indicating the channels are selective for potassium.

The relative contribution of BK current to the total macroscopic current was determined by pharmacologically dissecting the total $\mathrm{K}^{+}$current. In Figure $1 D$, the largest trace is the total macroscopic 
A

B

$10 \mu \mathrm{M}$ free- $\mathrm{Ca}^{2+}$
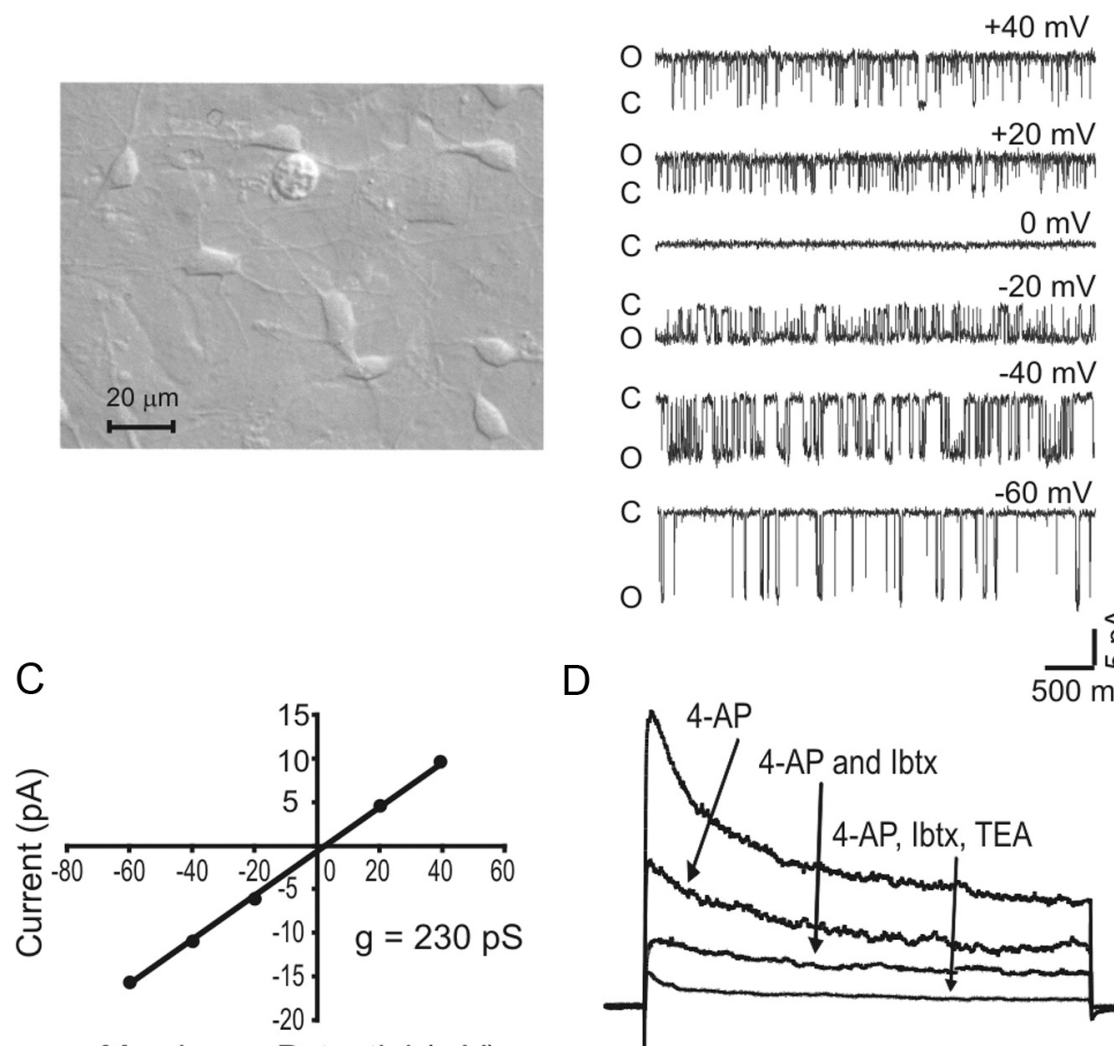

Membrane Potential (mV)
$\mathrm{D}$

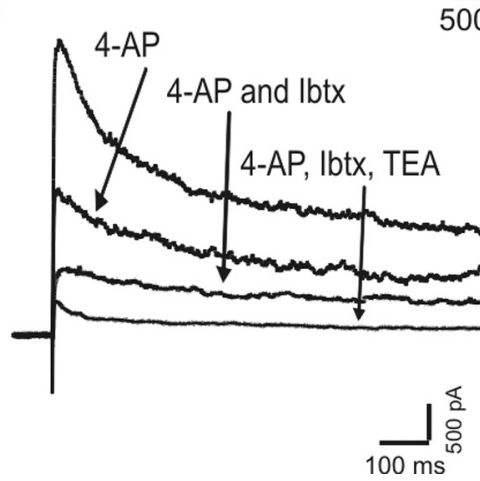

Figure 1. Conductance, voltage dependence, and pharmacology of BK channels in cultured striatal neurons. A, Digitally captured image of rat $\mathrm{P} 8$ striatal neurons 1 week in culture. $\boldsymbol{B}$, Time spent in the open state (inside-out configuration; $10 \mu \mathrm{m}$ free $\left.\mathrm{Ca}^{2+}\right)$ increases as the membrane is depolarized. $C$ and 0 represent the closed and open states, respectively. $C$, Plot of BK channel current amplitude as a function of membrane potential. A linear fit of this relationship $(r=0.99)$ gave a BK channel unitary conductance of $230 \mathrm{pS}$. D, Pharmacological dissection of the macroscopic potassium current in striatal neurons. Macroscopic currents were evoked by stepping from a holding potential of $-60 \mathrm{mV}$ to $+80 \mathrm{mV}$. The largest trace is the total current, recorded in normal Locke's solution containing $2.2 \mathrm{~mm}$ calcium. Addition of the $I_{\mathrm{A}}$ channel inhibitor 4-AP $(1 \mathrm{mM})$ removes the fast inactivating $I_{A}$. Perfusion with $100 \mathrm{~nm}$ Ibtx specifically blocks BK channels leaving a 4-AP-and lbtx-resistant current. Finally, addition of $100 \mathrm{~mm}$ TEA-Cl, a blocker of voltage-dependent potassium channels, leaves a small residual current (smallest trace). In all subsequent figures, $I_{A}$ is subtracted from the macroscopic current by inclusion of $1 \mathrm{~mm} 4-\mathrm{AP}$.

$\mathrm{K}^{+}$current, recorded in normal Locke's solution containing $2.2 \mathrm{~mm}$ calcium. Addition of the $I_{\mathrm{A}}$ channel inhibitor 4-AP (1 mM) blocks the fast inactivating $I_{\mathrm{A}}$ and indicates that $43 \pm 5 \%$ of the total current is due to $I_{\mathrm{A}}$. Perfusion with $100 \mathrm{~nm}$ Ibtx specifically blocks BK channels, leaving a 4-AP- and Ibtx-resistant current, which indicates that the BK channel contributes $27 \pm 7 \%$ of the total $\mathrm{K}^{+}$current. Finally, addition of $100 \mathrm{~mm}$ TEA-Cl, a blocker of voltage-dependent potassium channels, indicates that $25 \pm 3 \%$ of the total $\mathrm{K}^{+}$current is TEA sensitive. Striatal BK channels thus share the known features of BK channels, including potassium selectivity, large conductance $(>180$ pS), and sensitivity to iberiotoxin (McManus, 1991; Lippiat et al., 2003).

The relationship between duration of initial alcohol exposure and persistence of molecular tolerance is markedly nonlinear BK channels in freshly dissociated nucleus accumbens cell bodies are potentiated by ethanol (Martin et al., 2004). BK channels in cultured supraoptic nucleus neurons are also potentiated by ethanol, and develop two components of acute alcohol molecular tolerance (Pi- etrzykowski et al., 2004), consisting of a rapid reduction in potentiation, and a slowerdeveloping reduction in current density, which occurs after several hours.

The relationship between duration of initial alcohol exposure and persistence of acute tolerance was determined in cellattached patches from medium spiny neurons preexposed to $20 \mathrm{mM} \mathrm{EtOH}$ for 1 , 3 , or $6 \mathrm{~h}$ followed by various withdrawal periods, and subsequent challenge with 50 $\mathrm{mm}$ ethanol $(0.23 \mathrm{mg} \%)$. Single-channel traces in Figure 2, $A-C$, illustrate that while significant recovery from acute tolerance has occurred within $4 \mathrm{~h}$ of withdrawal from a $3 \mathrm{~h}$ exposure (Fig. 2A), neurons initially exposed for $6 \mathrm{~h}$ did not show comparable recovery at the $4 \mathrm{~h}$ withdrawal time point (Fig. 2 B). Furthermore, the persistence of acute tolerance was surprisingly long, with sensitivity still suppressed after $24 \mathrm{~h}$ withdrawal (Fig. 2C). These data establish that, indeed, there is a transition triggered after $6 \mathrm{~h}$, but not after 1 or $3 \mathrm{~h} \mathrm{EtOH}$ exposure, that results in persistent molecular tolerance. The data also show that continued exposure to $\mathrm{EtOH}$ is not necessary for the maintenance of tolerance after the molecular transition is initiated.

\section{Exploring the transition to PMT}

Previously published data have established the profound influence of alternative splicing of the $\alpha$ subunit in determining alcohol sensitivity and tolerance (Pietrzykowski et al., 2008). A recently described, novel method of producing BK molecular tolerance involves an alcohol-mediated upregulation of microRNA-9 and the consequent destruction of a subset of BK $\alpha$-subunit mRNAs containing a complementary sequence for miR-9. The remaining transcripts, especially STREX, encode alcohol-resistant BK channel proteins (Pietrzykowski et al., 2008). We hypothesized that the time-dependent changes in BK properties observed in striatal neurons might be explained by a timedependent shift in $\alpha$ subunit isoforms, such that STREX, the EtOH-insensitive variant, predominates. We took a threefold approach, to determine whether the $3 \mathrm{~h}$ versus $6 \mathrm{~h}$ transition to persistent ethanol tolerance can be attributed to changes in the predominant $\alpha$ isoform. First, we determined the mRNA levels of different BK channel isoforms during withdrawal from 3 and $6 \mathrm{~h}$ ethanol exposure. Second, we exogenously expressed various $\alpha$ splice variants in HEK 293 cells and compared their biophysical properties with those observed for BK in striatal culture. Finally, we used pharmacological tools to discriminate between splice variant populations based on their differential regulation by secondary signaling pathways (Chen et al., 2005). There are no commercially available antibodies to differentiate BK splice variants. Moreover, antibody studies will be problematic because the majority of BK splice sites are located intracellularly in the 
C-terminal tail (Xia et al., 2002; Krishnamoorthy et al., 2005). Thus, a description of which splice variants are functionally present in the membrane would be difficult using morphologic techniques. This necessitated this correlative approach, rather than a more direct one, such as determining protein levels using immunoblotting procedures.

\section{STREX mRNA is upregulated during} withdrawal from $6 \mathrm{~h}$ but not $3 \mathrm{~h} \mathrm{EtOH}$

The BK ALCOREX, Insertless, and STREX $\alpha$ subunit isoforms are all present in alcohol naive striatal neurons (Pietrzykowski et al., 2008). ALCOREX and Insertless are relatively sensitive to $50 \mathrm{~mm} \mathrm{EtOH}$, while STREX is resistant (Pietrzykowski et al., 2008). Therefore, we postulated that during withdrawal from $6 \mathrm{~h}$ alcohol exposure STREX becomes dominant. Specific primers to STREX were designed (see Materials and Methods) to test this. STREX was upregulated after $6 \mathrm{~h}$ of exposure to $20 \mathrm{~mm}$ $\mathrm{EtOH}(3.11 \pm 0.18$-fold compared with control; $n=6$, experiments performed in triplicate); there was no similar upregulation after $3 \mathrm{~h}$ EtOH exposure (Fig. 3). Furthermore, this upregulation was sustained, returning to baseline only after $24 \mathrm{~h}$ (Fig. 3). We also included primers for the auxiliary BK subunit $\beta 1$, which is detected at low levels in the striatum (Martin et al., 2004) and other brain regions (Jiang et al., 1999), and has been reported to confer alcohol resistance (FeinbergZadek and Treistman, 2007). $\beta 1 \mathrm{mRNA}$, which was present at low levels, did not significantly differ from control during withdrawal from either 3 or $6 \mathrm{~h} \mathrm{EtOH}$ exposure (one-way ANOVA, $p=0.97$ ).

\section{Neuronal BK characteristics during withdrawal from 3 versus $6 \mathrm{~h}$ EtOH exposure}

The calcium sensitivity, activation rate, and mean open and closed times of BK were determined during withdrawal.

\section{Gating kinetics of BK are altered after withdrawal from $6 \mathrm{~h}$ but not $3 \mathrm{~h}$ alcohol exposure}

To study BK current kinetics we summed 100 repetitively evoked single-channel sweeps into a cumulative current trace, rather than using whole-cell macroscopic analysis. The cumulative current trace resembles the classical macroscopic current recorded in the wholecell patch-clamp configuration, but assures the absence of even very small contaminating currents that might influence kinetic analysis using whole-cell macroscopic methodology. The potential of an outside-out patch was stepped, in the presence of $10 \mu \mathrm{M}$ free $\mathrm{Ca}^{2+}$, from $-60 \mathrm{mV}$ holding to either $+40 \mathrm{or}+60 \mathrm{mV}$, to elicit an open channel probability $\left(\mathrm{NP}_{\mathrm{o}}\right)$ of $\sim 0.5$. A typical example showing 6 of 100 consecutive single-channel traces from patches preexposed to 20 $\mathrm{mm}$ EtOH for either 3 or $6 \mathrm{~h}$, and then ethanol-withdrawn for $24 \mathrm{~h}$, is shown in Figure $4 A-C$. Figure 4, $D-F$, illustrates the compiled macroscopic current from these same patches. All of the activation rates were fit by a single exponential (averaged values): $\tau=2.70 \pm$ $0.25 \mathrm{~ms}(n=3)$ for naive channels, $2.34 \pm 0.33 \mathrm{~ms}(n=3)$ for channels preexposed to $3 \mathrm{~h} \mathrm{EtOH}$ and withdrawn for $24 \mathrm{~h}$, and $19.15 \pm 3.12 \mathrm{~ms}(n=3)$ for channels preexposed to $\mathrm{EtOH}$ for $6 \mathrm{~h}$ and withdrawn for $24 \mathrm{~h}$. Although activation rate can be voltage

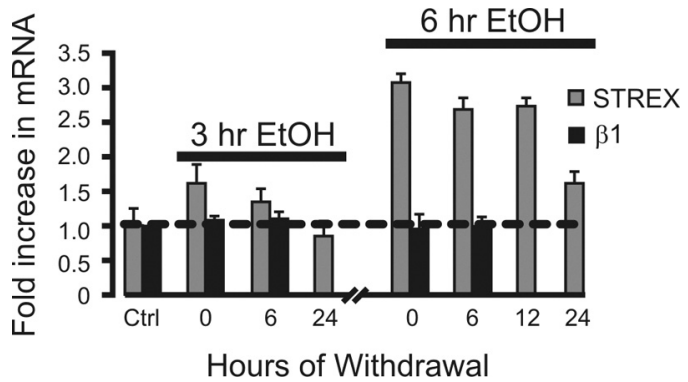

Figure 3. Six, but not $3 \mathrm{~h}$ of $20 \mathrm{~mm}$ EtOH induces an upregulation of STREX mRNA during withdrawal. $m R$ NA levels in cultured striatal neurons were measured by real-time $P C R$ with primers to $\alpha$-STREX and to the $\beta 1$ subunit. Immediately after $6 \mathrm{~h}$ of exposure to $20 \mathrm{~mm}$ EtOH, STREX mRNA increased approximately threefold compared with control. Bar graphs represent the mean \pm SEM for six independent experiments performed in triplicate. Statistical significance was determined using one-way ANOVA; ${ }^{*} p<0.05$.

dependent, we found that the voltage dependence, determined from the slope of $G / G_{\max }$ (see below) of BK channels from all experimental categories was very similar $(e$ range $=0.98-1.10)$ across the voltage range tested (data not shown). Thus, the activation rate is markedly slower in patches from neurons in withdrawal from $6 \mathrm{~h}$ $\mathrm{EtOH}$ exposure, compared with those withdrawn from $3 \mathrm{~h}$ alcohol exposure ( $p<0.01$, Student's $t$ test), or alcohol-naive neurons.

There is a shift in BK channel calcium sensitivity after a $6 \mathrm{~h}$, but not a $3 \mathrm{~h}$, exposure to EtOH

$G / G_{\max }$ was derived from a series of macroscopic currents obtained with either 1 or $10 \mu \mathrm{M}$ free $\mathrm{Ca}^{2+}$ in the recording pipette, in the presence of $1 \mathrm{~mm} 4$-AP to block $I_{\mathrm{A}}$. We found a leftward shift in the $G-V$ relationship (Fig. 5), indicative of increased $\mathrm{Ca}^{2+}$-responsiveness, during withdrawal from a $6 \mathrm{~h}$ but not $3 \mathrm{~h}$ exposure to $20 \mathrm{~mm} \mathrm{EtOH} \mathrm{(left} \mathrm{and} \mathrm{middle} \mathrm{panels).} \mathrm{As} \mathrm{would} \mathrm{be}$ expected, this shift was not immediately apparent, presumably 
A

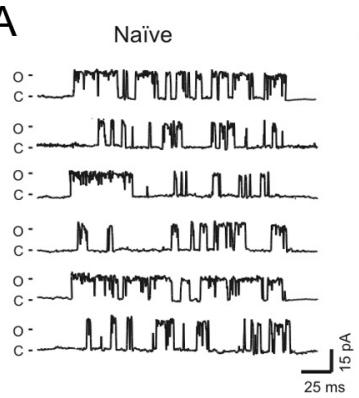

B

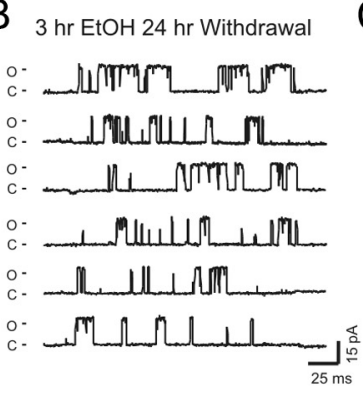

\section{C}
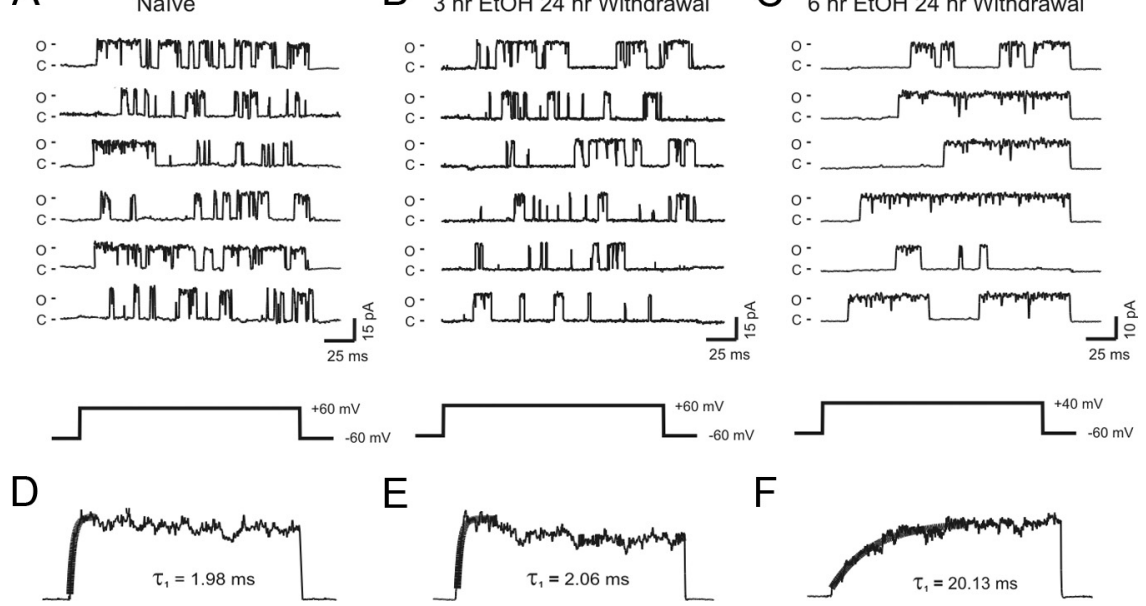

$\mathrm{E}$

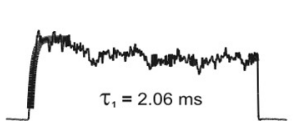

$\mathrm{F}$

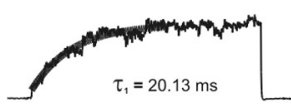

Figure 4. Kinetic properties of $B K$ channels differ from control during withdrawal from a $6 \mathrm{~h}$, but not a $3 \mathrm{~h}$ exposure to $20 \mathrm{~mm}$ EtOH. $\boldsymbol{A}-\boldsymbol{C}$, A series of six consecutive $B K$ traces evoked by depolarizing channels that were naive $(\boldsymbol{A})$, preexposed to $20 \mathrm{~mm}$ Et $0 \mathrm{H}$ for $3 \mathrm{~h}$ and with ethanol withdrawn for $24 \mathrm{~h}(\boldsymbol{B})$, or preexposed to $20 \mathrm{~mm}$ EtOH for $6 \mathrm{~h}$ and with ethanol withdrawn for $24 \mathrm{~h}$ (C). Channel activity was recorded in an outside-out patch with $10 \mu \mathrm{m}$ free $\mathrm{Ca}^{2+}$ in the recording electrode. Cumulative current was compiled from 100 single-channel traces. Current activation was best fit with a single exponential. The use of different voltage steps used in $A$ and $\boldsymbol{B}$ versus $C$ reflects the need to maintain constant $P_{0}$ values in light of the shift in the $P_{0}-V$ curve after transition to PMT. Compiled currents shown in $\mathbf{D}-\boldsymbol{F}$ were obtained at the same potentials as the traces shown in $\boldsymbol{A}-\boldsymbol{C}$.

\section{$1 \mu \mathrm{M}$ free-Ca ${ }^{2+}$}
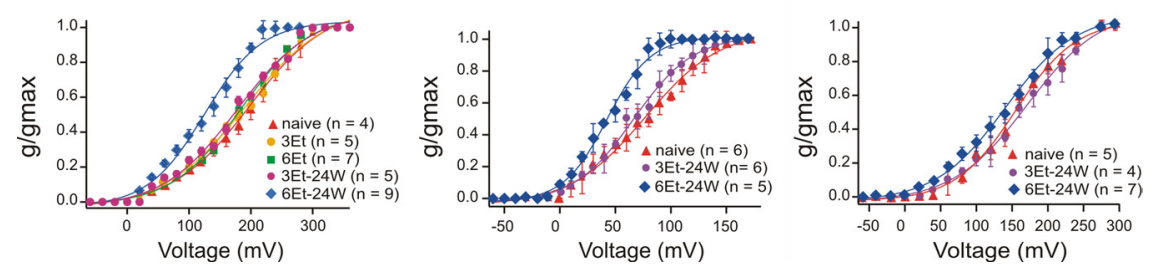

Figure 5. There is a leftward shift in $\mathrm{G}-V$ relationship present after withdrawal from a $6 \mathrm{~h}$ but not $3 \mathrm{~h}$ exposure to $20 \mathrm{~mm} \mathrm{EtOH}$. Plots of $\mathrm{G}-V$ relationship for macroscopic currents obtained with $1 \mu \mathrm{m}$ free $\mathrm{Ca}^{2+}$ (left graph), or $10 \mu \mathrm{m}$ free $\mathrm{Ca}^{2+}$ (middle graph). Graph on right was obtained with $10 \mu \mathrm{m}$ free $\mathrm{Ca}^{2+}$ in the recording pipette and $100 \mathrm{~nm} \mathrm{lbtx} \mathrm{in} \mathrm{the} \mathrm{bath.} \mathrm{BK} \mathrm{currents} \mathrm{were} \mathrm{evoked}$ from a holding potential of $-70 \mathrm{mV}$ with $+10 \mathrm{mV}$ (left and middle graph) or $+20 \mathrm{mV}$ (right graph) incremental voltage steps. Macroscopic currents were measured at steady-state condition, $450-490 \mathrm{~ms}$ after the beginning of the voltage step. Bath contained $1 \mathrm{~mm} 4-\mathrm{AP}$ to block $I_{\mathrm{A}}$ current.

requiring the translation, trafficking, and insertion of the protein following the $6 \mathrm{~h}$ exposure. To confirm that the shift in the $G-V$ relationship in these cultured striatal neurons was attributable to a change in the BK channel current, we blocked BK current with $100 \mathrm{nM}$ Ibtx. This concentration of Ibtx is specific for BK (Hanner et al., 1998; Behrens et al., 2000; Meera et al., 2000; Lippiat et al., 2003). Ibtx blocked the shift in the $G-V$ relationship (Fig. 5, column 3) consistent with the proposition that the shift is attributable to a time-dependent change in the BK current.

\section{Single-channel kinetics}

We next examined the mean open and closed times of single channels in cell-attached patch-clamp mode. Representative traces of single BK channels that were naive, or preexposed to $20 \mathrm{~mm} \mathrm{EtOH}$ for 3 or $6 \mathrm{~h}$, and ethanol withdrawn for $24 \mathrm{~h}$ are shown in Figure $6 \mathrm{~A}-\mathrm{C}$, respectively. Channel activity was evoked by stepping from a holding potential of $-60 \mathrm{mV}$ to a potential of $+70 \mathrm{mV}$ for the traces recorded in panels $\mathrm{A}$ and $\mathrm{B}$, or $+50 \mathrm{mV}$ for the traces recorded in panel $\mathrm{C}$, to yield a consistent $\mathrm{NP}_{\mathrm{o}} \approx 0.5$. The dwell time distribution of single-channel patches are shown in the histograms below the current traces. All of the open times distributions could be well fit with a single-component function, with $\tau=8.30 \pm 1.95 \mathrm{~ms}(n=4), 7.66 \pm$ $0.82 \mathrm{~ms}(n=4)$, and $18.80 \pm 3.76 \mathrm{~ms}(n=$ 3) for naive, $3 \mathrm{~h} \mathrm{EtOH} / 24 \mathrm{~h}$ withdrawn, and $6 \mathrm{~h} \mathrm{EtOH} / 24 \mathrm{~h}$ withdrawn channels, respectively. Thus, channels present during withdrawal from $6 \mathrm{~h}$ EtOH had significantly longer mean open times than either naive channels or channels during withdrawal from $3 \mathrm{~h}$ EtOH $(p<0.05$, Student's $t$ test).

In contrast to the open times distribution, the closed times distribution was best fit with a function containing two components, with $\tau_{\text {fast }}=4.1 \pm 1.9 \mathrm{~ms}$ and $\tau_{\text {slow }}=45.4 \pm 9.3 \mathrm{~ms}$ for naive channels, $\tau_{\text {fast }}=5.3 \pm 1.1 \mathrm{~ms}$ and $\tau_{\text {slow }}=57.8 \pm 4.4$ $\mathrm{ms}$ for channels in withdrawal for $24 \mathrm{~h}$ from $3 \mathrm{~h} \mathrm{EtOH}$, and $\tau_{\text {fast }}=64.1 \pm 10.8 \mathrm{~ms}$ and $\tau_{\text {slow }}=242.9 \pm 31.5$ for channels in withdrawal for $24 \mathrm{~h}$ from $6 \mathrm{~h} \mathrm{EtOH}$, indicative of a changeover to longer closures after $6 \mathrm{~h}$, but not $3 \mathrm{~h}$ exposure.

Table 1, summarizing the biophysical measurements in striatal neurons, indicates that BK channels present during withdrawal from $6 \mathrm{~h}$ but not $3 \mathrm{~h} \mathrm{EtOH}$ are more sensitive to calcium (indicated by a shift in $V_{1 / 2}$ to more hyperpolarized potentials), have a slower activation rate, and have much longer open and closed times. Overall, the BK channel characteristics observed during withdrawal after $6 \mathrm{~h}$ exposure to $\mathrm{EtOH}$ are consistent with those found in the literature characterizing STREX. This includes, e.g., the shift to the left of the $G / G_{\max }$ Gaussian curves (Xie and McCobb, 1998; Petrik and Brenner, 2007). One measurement equivocal with respect to STREX is the slowing of the kinetics observed after the $6 \mathrm{~h}$ exposure protocol. Xie and McCobb (1998) reported that the expression of STREX speeds BK current activation rate, the opposite of what we observed in our study. However, that study was performed in a very different preparation (i.e., oocytes vs HEK-293 cells), which may have different posttranscriptional mechanisms (e.g., phosphorylation) influencing channel kinetics. Interestingly, another study, by Petrik and Brenner (2007), shows that STREX does not affect BK channel kinetics. We next expressed a variety of BK $\alpha$ isoforms in HEK 293 cells to compare their properties with those observed in striatal channels.

\section{BK characteristics in transfected HEK-293 cells}

HEK-293 cells were transfected with EtOH-sensitive BK $\alpha$ subunit variants (Insertless and ALCOREX), and an EtOHinsensitive variant, STREX, and the same biophysical parameters were measured as had been measured in striatal neurons. Macroscopic current traces were obtained with $1 \mu \mathrm{M}$ free $\mathrm{Ca}^{2+}$ in the recording pipette (Fig. $7 A-C$ ), and kinetic characteristics were determined. As shown in Figure 7, $D$ and $E$, the STREX variant has a slowed activation rate $(\tau=12.7 \pm 2.7 \mathrm{~ms}, n=3)$, longer mean open time $(\tau=18.23 \pm 2.45 \mathrm{~ms}, n=5)$ and longer closed times $\left(\tau_{\text {fast }}=55.6 \pm 12.4 \mathrm{~ms}\right.$ and $\left.\tau_{\text {slow }}=205.8 \pm 19.3 \mathrm{~ms}, n=5\right)$ 
A Naïve ค.
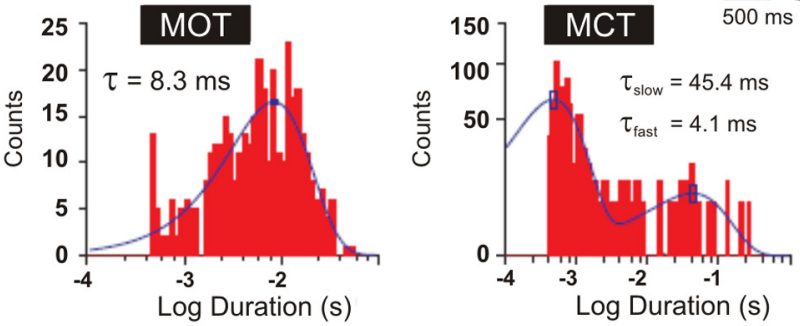

B
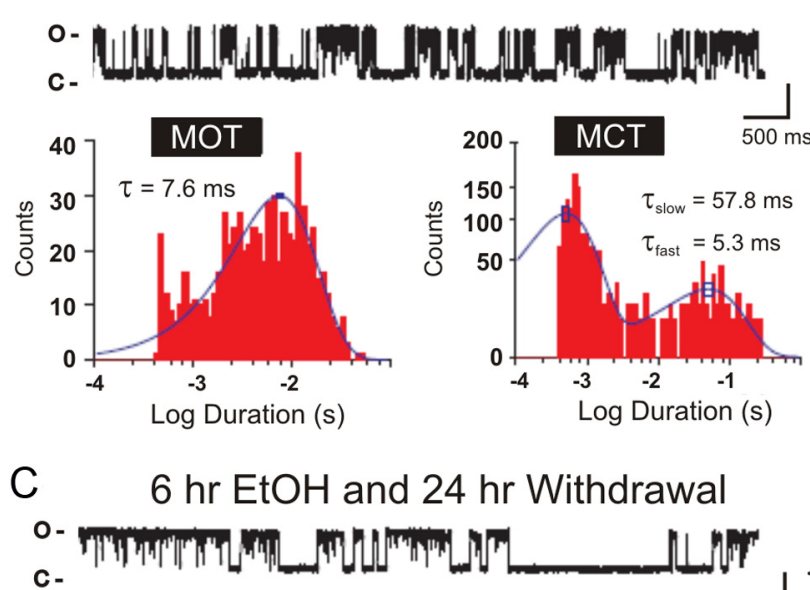

C -

\section{MOT}

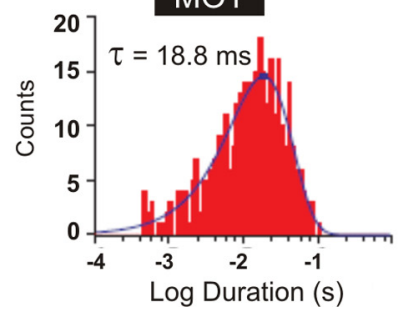

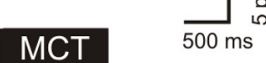

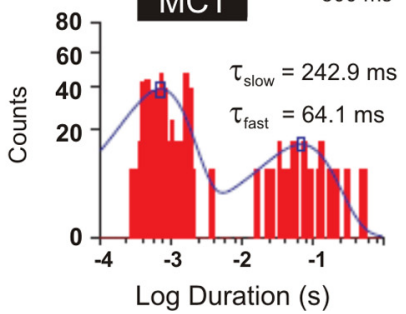

Figure 6. Mean open times (MOT) and closed times (MCT) are altered during withdrawal from a $6 \mathrm{~h}$ but not a $3 \mathrm{~h}$ exposure to $20 \mathrm{~mm} \mathrm{EtOH}$. $\mathrm{A}-\mathrm{C}$, Representative traces from single BK channels recorded in cell-attached patch-clamp mode from naive channels $(\boldsymbol{A})$, and neurons preexposed to $20 \mathrm{~mm} \mathrm{EtOH}$ for 3 or $6 \mathrm{~h}$, and with ethanol withdrawn for $24 \mathrm{~h}(\boldsymbol{B}, \boldsymbol{C})$. Channel activity was evoked by stepping from a holding potential of $-60 \mathrm{mV}$ to a potential of $+70 \mathrm{mV}$ for the traces recorded in $\boldsymbol{A}$ and $\boldsymbol{B}$ or to $+50 \mathrm{mV}$ for the traces recorded in $\boldsymbol{C}$. The dwell time distributions of single-channel patches are shown in the histograms below the current traces. Open and closed times were computed with half-amplitude threshold analysis. Curves were fitted using a maximum-likelihood minimization routine. The open times distribution could be well fitted with a single-component function while the closed time distribution was well fitted with a double exponential.

(Table 1) than the other variants tested, similar to channels present during withdrawal from $6 \mathrm{~h}$ (but not $3 \mathrm{~h}$ ) of alcohol exposure. $G / G_{\max }$ curves were generated (Fig. $7 D$ ) as described previously. As seen in Table 1, the STREX and Insertless $V_{1 / 2}$ (the potential defining half maximal activation) are lessened (126.63 $\pm 10.1 \mathrm{mV}$ $(n=7)$ and $117.6 \pm 9.9 \mathrm{mV}(n=10)$, respectively) just as the $V_{1 / 2}$ for BK channels in neurons after $6 \mathrm{~h} \mathrm{EtOH}$ exposure and 24 withdrawal are lessened $(115.4 \pm 12.8 \mathrm{mV}(n=9)$. These data, summarized in Table 1, indicate that the properties of channels present in the membrane after $6 \mathrm{~h}$ exposure and $24 \mathrm{~h}$ withdrawal are similar to heterologously expressed STREX, consistent with the hypothesis that the STREX isoform predominates after $6 \mathrm{~h}$ of exposure.

\section{Striatal currents are inhibited by PKA activation during withdrawal from $6 \mathrm{~h}$ but not $3 \mathrm{~h} \mathrm{EtOH}$}

Alternatively spliced $\alpha$ isoforms are differentially regulated by secondary signaling pathways, and we used this as a tool to further test the hypothesis that STREX isoforms predominate in striatal culture after 6 , but not $3 \mathrm{~h} \mathrm{EtOH}$ exposure, by assessing the actions of the PKA activator, 8-bromo-cAMP. Chen et al. (2005) have shown that STREX is inhibited by cAMP while other isoforms such as Insertless are potentiated (Chen et al., 2005). This differential response is attributable to an additional PKA site in the 58 aa STREX insert in the C-terminal tail (Chen et al., 2005). Figure 8 shows macroscopic currents evoked by steps to $+80 \mathrm{mV}$ from a holding potential of $-60 \mathrm{mV}\left(1 \mu \mathrm{m}\right.$ free $\mathrm{Ca}^{2+}$ in the pipette) after various ethanol exposures and withdrawal periods. Currents from naive neurons or neurons exposed to ethanol for $3 \mathrm{~h}$ and withdrawn for $24 \mathrm{~h}$ were potentiated by extracellular perfusion with $250 \mu \mathrm{M} 8$-bromo-cAMP ( $41.5 \pm 8.43$ and $35.94 \pm 10.7 \%$, respectively). In sharp contrast, currents from neurons exposed to ethanol for $6 \mathrm{~h}$ and withdrawn for $24 \mathrm{~h}$ were markedly inhibited $(32.9 \pm 15.1 \%)$ by 8 -bromo-cAMP (Fig. $8 \mathrm{~F}$ ) consistent with studies showing that STREX channel activity is reduced by this agonist. Interestingly, immediately following either 3 or $6 \mathrm{~h} \mathrm{EtOH}$ exposure, 8-bromo-cAMP did not have a significant effect $(-4.0 \pm 3.6$ and $-8.7 \pm 6.2 \%$ respectively). This may reflect a change in the phosphorylation level of BK channels induced by alcohol that persists when the drug remains present.

\section{The 3-6 h transition can be observed in vivo}

We next asked whether the transition in persistence of tolerance observed between 3 and 6 h exposure in cultured striatal neurons in vitro could be observed after in vivo exposure in mice. One of the concerns with cultures of striatal neurons is that they are electrically silent because the cultures consist principally of GABAergic inhibitory neurons lacking excitatory inputs. Thus, it is important to show that the temporal shift in molecular tolerance is not simply a function of the cultures. For our in vivo studies, we used C57BL/6J mice. The rationale for use of mice rather than rats for this part of the study was predicated upon two considerations: (1) previous in vivo studies examining the role of $\mathrm{BK}$ in alcohol tolerance were performed with $\mathrm{KO}$ mice (Martin et al., 2008), providing the potential to use KO technology in future studies of BK and the transition to PMT, and (2) the results provide insight into the generality of the phenomenon between different rodent models.

We first determined a protocol of intraperitoneal injection of EtOH that mimicked the temporal and concentration characteristics used in the in vitro exposure protocol. In injected animals, ethanol is absorbed directly from the peritoneal cavity into the portal bloodstream, where it travels to the liver and is metabolized by hepatic alcohol dehydrogenase. Differences in metabolism of EtOH across gender, body weight, species and other factors determine the concentration of ethanol that actually reaches the brain. Crippens et al. (1999), used microdialysis to measure alcohol concentrations in the brain versus concentrations in the tail blood of adult rodents after intraperitoneal administration of ethanol, and consistently found that ethanol concentrations in the brain were significantly lower than in blood samples. Therefore, we selected an EtOH concentration that might better approximate the concentration range used for the in vitro experiments. 
Table 1. Biophysical measurements in striatal neurons

\begin{tabular}{|c|c|c|c|c|}
\hline & Activation rate (ms) & MOT (ms) & MCT (ms) & $V_{1 / 2}(\mathrm{mV})$ \\
\hline \multicolumn{5}{|l|}{ Striatum } \\
\hline Naive & $2.70 \pm 0.25$ & $9.13 \pm 1.95$ & $\tau_{\text {fast }}=6.71 \pm 1.89, \tau_{\text {slow }}=60.80 \pm 9.32$ & $157.23 \pm 24.77$ \\
\hline $3 \mathrm{Et}-24 \mathrm{~W}$ & $2.34 \pm 0.33$ & $7.86 \pm 0.82$ & $\tau_{\text {fast }}=5.52 \pm 1.14, \tau_{\text {slow }}=53.44 \pm 4.37$ & $146.23 \pm 18.21$ \\
\hline 6Et-24W & $19.15 \pm 3.12$ & $21.49 \pm 3.76$ & $\tau_{\text {fast }}=70.26 \pm 10.84, \tau_{\text {slow }}=230.33 \pm 31.49$ & $115.39 \pm 12.84$ \\
\hline \multicolumn{5}{|c|}{ 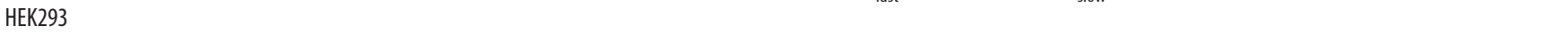 } \\
\hline Insertless & $2.17 \pm 0.53$ & $8.56 \pm 1.86$ & $\tau_{\text {fast }}=1.92 \pm 0.98, \tau_{\text {slow }}=24.23 \pm 8.78$ & $126.63 \pm 10.11$ \\
\hline P27 & $1.50 \pm 0.34$ & $6.47 \pm 1.50$ & $\tau_{\text {fast }}=8.39 \pm 2.94, \tau_{\text {slow }}=45.21 \pm 7.72$ & $165.12 \pm 22.34$ \\
\hline STREX & $12.74 \pm 2.68$ & $18.23 \pm 2.45$ & $\tau_{\text {fast }}=55.61 \pm 12.38, \tau_{\text {slow }}=205.75 \pm 19.27$ & $117.64 \pm 9.95$ \\
\hline
\end{tabular}

MOT, Mean open times; $\mathrm{MCT}$, mean closed times; $\mathrm{ET}$, EtOH exposure (preceding number is hours of exposure); $\mathrm{W}, \mathrm{Et} \mathrm{OH}$ withdrawn (preceding number is hours of withdrawal).

A

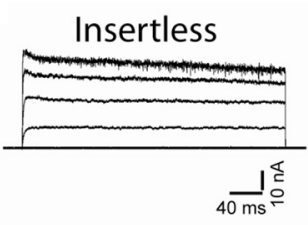

$\mathrm{D}$

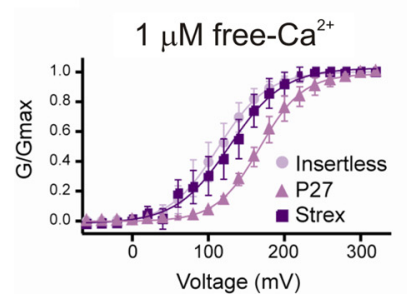

B

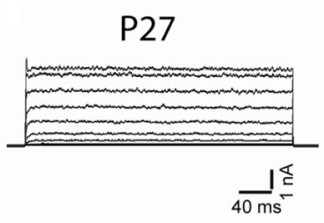

$\mathrm{E}$

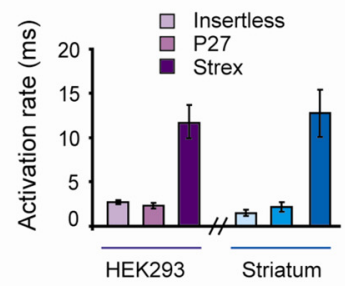

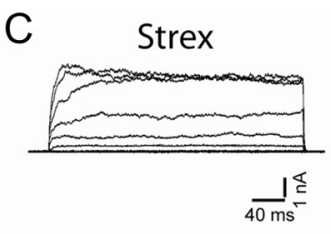

F

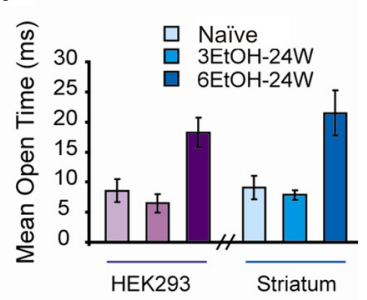

Figure 7. Biophysical properties of BK $\alpha$ splice variants exogenously expressed in HEK293 cells. A-C, Macroscopic BK currents: Insertless ( $\boldsymbol{A})$, ALCOREX (B), or STREX (C), evoked from a holding potential of $-60 \mathrm{mV} . \boldsymbol{D}, \mathrm{G}-V$ relationship of Insertless (circles), ALCOREX (triangles), and STREX (squares). $\boldsymbol{E}, \boldsymbol{F}$, Bar graphs of time constants of activation ( $\boldsymbol{E}$ ) and mean open time ( $\boldsymbol{F}$ ), for BK $\alpha$ isoforms in HEK cells and for BK in striatal neurons. All measurements in HEK cells were performed similarly to those previously described for neurons.

Hourly EtOH intraperitoneal injections were administered. The first injection $(1.8 \mathrm{~g} / \mathrm{kg}$, i.p. $)$ was followed by booster injections $(1.2$ $\mathrm{g} / \mathrm{kg}$, i.p.) for two or five subsequent injections. These injections produced blood ethanol concentrations of $\sim 40 \mathrm{~mm}(0.18 \mathrm{mg} \%)$, that returned to baseline levels within $1 \mathrm{~h}$ following final injection (Fig. 9). After each injection protocol, the animal was maintained for $24 \mathrm{~h}$, and then killed, and a dish of acutely dissociated striatal neurons prepared for patch-clamp analysis of BK molecular tolerance. A combination of immunohistochemistry and viability testing (see Materials and Methods; data not shown) assured that the isolated neurons were healthy, and were striatal medium spiny neurons. The outcome in vivo was remarkably similar to what had been observed in vitro. Significant potentiation of BK was evident during acute challenge with ethanol in neurons from mice that had been exposed for three injections and withdrawn for $24 \mathrm{~h}$, whereas BK channels recorded in neurons from mice that had been exposed to six injections were resistant, indicative of persistent molecular tolerance (Fig. 9).

\section{Discussion}

We provide evidence that there are time-dependent transitions, initiated by drug exposure, that determine characteristics of acute molecular tolerance. Tolerance, once induced, does not require the continued presence of the drug. Furthermore, the persistence of acute tolerance is dependent upon the duration of initial alcohol exposure. Our data suggest that longer-persistence tolerance may be explained by an increase in an alcohol-insensitive BK channel isoform called STREX. We do not know the fine temporal structure of the transition from shorter- to longer-duration molecular tolerance that occurs between 3 and $6 \mathrm{~h}$. Moreover, although our data are consistent with the upregulation of STREX as the causative agent of the transition to more persistent tolerance, we cannot rule out other routes, such as a time-dependent phosphorylation. Behavioral studies have shown that the development of tolerance after short alcohol exposures is dependent upon exposure protocol. For example, in mice and rats, a single intraperitoneal administration of EtOH reduces motor impairment and hypothermic response to a second dose administered 8-24 h after the first dose (Crabbe et al., 1979; Khanna et al., 1996). These studies also demonstrated that higher initial doses of alcohol produced the greatest degree of tolerance. Furthermore, the fact that the degree of tolerance was approximately equivalent after a single intraperitoneal dose of $4 \mathrm{~g} / \mathrm{kg}$ versus two successive doses of $2 \mathrm{~g} / \mathrm{kg}$ suggested that peak blood alcohol concentration was not as important as duration of alcohol exposure (Khanna et al., 1996). Numerous studies suggest the existence of alcohol triggered molecular "switches" that may contribute to the formation of behavioral tolerance. For example, changes in biochemical pathways can outlast the presence of the initiating drug of abuse and therefore qualify as drug-activated switches (Pandey et al., 2001, 2003; Borlikova et al., 2006). Examples of potential drug-activated molecular switches include transcription factors such as $\delta$ fosB and CREB (Kelz et al., 1999; Nestler et al., 2001; Hyman et al., 2006; Renthal et al., 2008) and secondary signaling molecules such as PKA (Coe et al., 1996; Pandey et al., 2001; Lin et al., 2006). In flies, CREB, which is activated by PKA, mediates upregulation of $\mathrm{d}$ slo during rapid tolerance to benzyl alcohol (Wang et al., 2007).

\section{Six hour time point}

Six hours of drug exposure is emerging as an important temporal threshold for a number of phenomena related to drug tolerance and addiction. For example, escalation of cocaine selfadministration occurs after $6 \mathrm{~h}$, but not $1 \mathrm{~h}$ of drug access (Ahmed and Koob, 1998). Ben-Shahar et al. (2006) found that $6 \mathrm{~h}$, but not $1 \mathrm{~h}$, of daily access to self-administered cocaine results in elevated levels of dopamine transporter (Ben-Shahar et al., 2006). Ethanol promotes translocation of the catalytic subunit of PKA from the Golgi area to the nucleus after $6 \mathrm{~h}$, but not $1 \mathrm{~h}$ of drug exposure (Dohrman et al., 2002). To our knowledge, there have not yet been any studies showing that a single exposure 


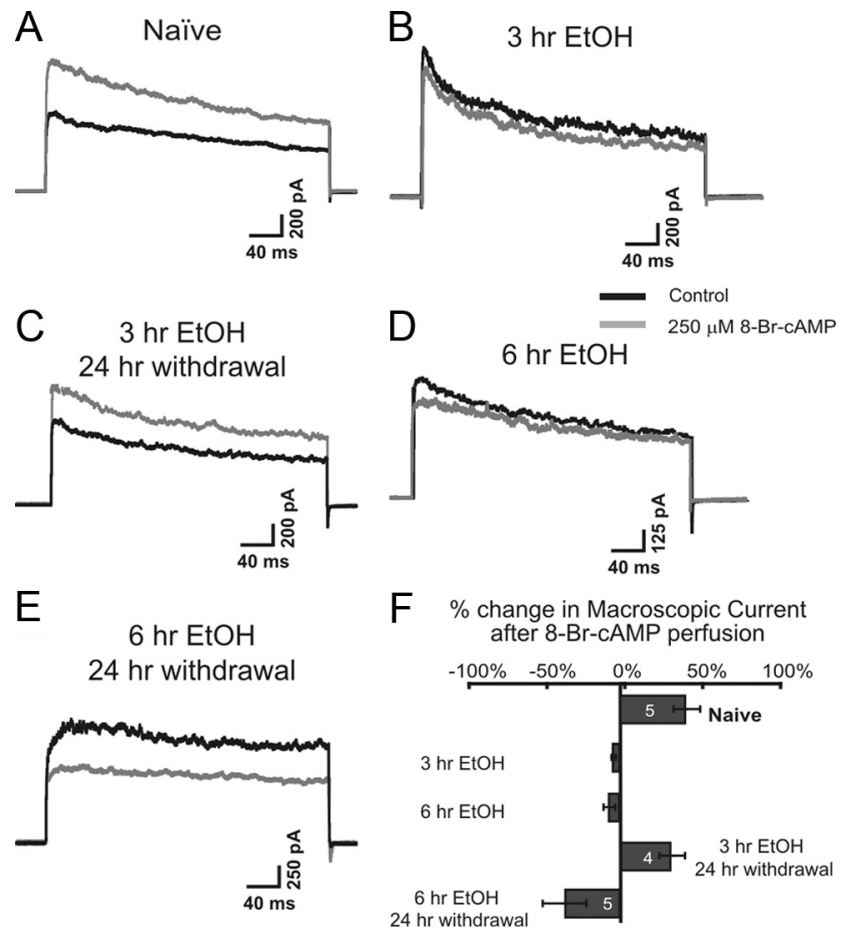

Figure 8. Effect of 8-bromo-cAMP, a PKA activator, on striatal currents after various exposures to $20 \mathrm{~mm}$ EtOH. $A-E$, Macroscopic currents from neurons that are naive $(A)$, Et0H exposed for $3 \mathrm{~h}(\boldsymbol{B})$, EtOH exposed for $3 \mathrm{~h}$ and withdrawn for $24 \mathrm{~h}(\boldsymbol{C})$, EtOH exposed for $6 \mathrm{~h}(\boldsymbol{D})$, and ethanol exposed for $6 \mathrm{~h}$ and withdrawn for $24 \mathrm{~h}(\boldsymbol{E})$. Traces are before (black) and after (gray) perfusion with $250 \mu \mathrm{m}$ 8-bromo-cAMP. All macroscopic currents were recorded in the presence of $1 \mathrm{~mm} 4-\mathrm{AP}$, stepped from a holding potential of $-60 \mathrm{mV}$ to $+80 \mathrm{mV}$, with $1 \mu \mathrm{m}$ free $\mathrm{Ca}^{2+}$ in the recording pipette. $\boldsymbol{F}$, Tabulation of the effects of 8 -bromo-cAMP.

to alcohol results in escalated drinking. Indeed, in light of our results, it would be interesting to examine whether the duration of a single drinking bout influences subsequent alcohol drinking pattern, as with cocaine usage.

Our data may implicate a recently described mechanism involving miR-9, a representative of the class of small modulatory RNAs known as microRNAs (Pietrzykowski et al., 2008). Within 15 min of exposure, alcohol increases miR-9 levels in hypothalamic and striatal neurons, resulting in the selective and rapid degradation of those BK transcripts containing a sequence with complementarity to miR-9 (Pietrzykowski et al., 2008). Those transcripts that were degraded encoded channel isoforms with the highest sensitivity to alcohol. For example, the transcript levels of ALCOREX, which form a channel highly sensitive to ethanol, were greatly degraded, whereas STREX transcripts, which form a channel insensitive to ethanol, were relatively enriched. Thus, although not tested here, our data are consistent with a mechanism whereby the emergent predominance of STREX mRNA represents a time-dependent transition involving miR-9. However, this scenario contains an issue requiring further exploration. Upregulation of miR-9 occurs rapidly after exposure to ethanol, evident within 15 min (Pietrzykowski et al., 2008), and well developed before a putative $6 \mathrm{~h}$ transition time point. One potential explanation consistent with our data would require that the duration of ethanol exposure influence either the duration or consequences of miRNA upregulation. These parameters are currently unknown. Additionally, the increase in STREX returns to baseline after $24 \mathrm{~h}$, yet at that time, the increase in response to ethanol is still suppressed. Clearly, a fuller understanding of the mechanistic underpinnings of the time-dependent transition re-
A
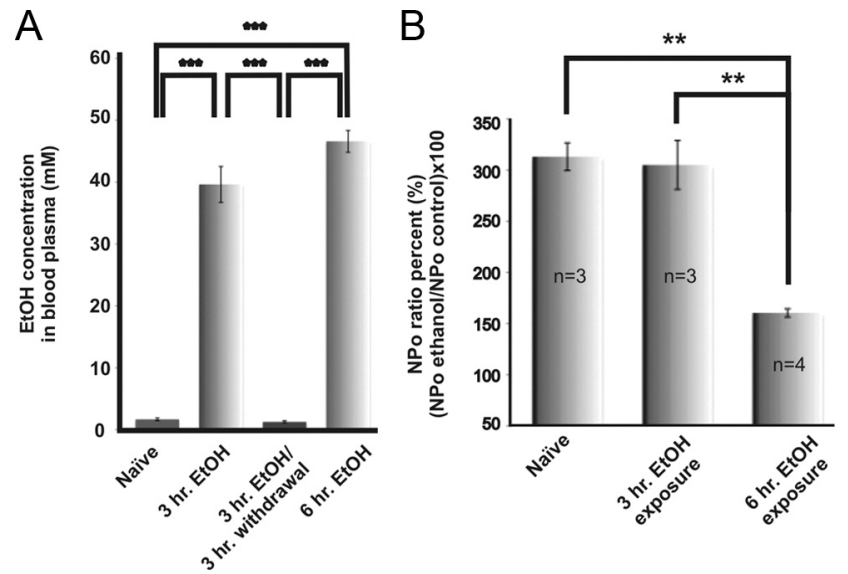

Figure 9. In vivo $\mathrm{EtOH}$ injections mimic in vitro results. $\boldsymbol{A}$, Blood alcohol concentrations in C57BL/6J mice: naive (no injection: $n=4), 1 \mathrm{~h}$ after the third injection of EtOH $(n=4)$, $3 \mathrm{~h}$ after the third injection $(n=3)$, and $1 \mathrm{~h}$ after the sixth EtOH injection $(n=4)$. One-way ANOVA, Tukey post hoc, ${ }^{* * *} p=0.001$. Hourly EtOH intraperitoneal injections were administered. The first injection ( $1.8 \mathrm{~g} / \mathrm{kg}$, i.p.) was followed by booster injections ( $1.2 \mathrm{~g} / \mathrm{kg}$, i.p.) every hour for two or five subsequent injections (see Results for further explanation). $\boldsymbol{B}$, Effect of $50 \mathrm{~mm}$ EtOH challenge on BK channel activity in dissociated striatal neurons obtained from mice $24 \mathrm{~h}$ after in vivo alcohol exposure for either 3 or $6 \mathrm{~h}$. There is significant molecular tolerance remaining after the $6 \mathrm{~h}$ exposure, but not after the $3 \mathrm{~h}$ exposure. Calculation of $\mathrm{NP}_{0}$ was performed with Igor Pro 6.1 Wave Metrics software. Statistical differences were determined using Student's $t$ test: ${ }^{* *} p<0.002$.

quires a greater understanding than we currently have of the temporal dynamics between mRNA changes, BK synthesis, and channel trafficking and insertion.

Here, we describe a mechanism underlying molecular tolerance to alcohol involving a switch in the $\alpha$ subunit isoform composition of BK channels. Indeed, our approach was designed to test this possibility. Moreover, there may be additional benefits inherent to this emerging picture. For example, the substitution of STREX for preexisting BK isoforms not only reduces the sensitivity to alcohol, but increases the sensitivity to $\mathrm{Ca}^{2+}$, important in light of the concurrent inhibition of $\mathrm{Ca}^{2+}$ channels produced by the drug (Wang et al., 1991). However, other mechanisms also play a role in BK acute tolerance. These include short-duration posttranscriptional changes such as phosphorylation/dephosphorylation, as well as more lasting alterations such as membrane lipid modification (Yuan et al., 2008; Treistman and Martin, 2009), and epigenetic phenomena such as chromatin remodeling (Wang et al., 2007, 2009). Why do multiple and seemingly redundant BK adaptive mechanisms, such as both desensitization and subsequent internalization exist? This is likely necessitated by the particularly large conductance of the channel, such that persistent potentiation would lead to serious nervous system dysfunction.

In a previous study (Pietrzykowski et al., 2008) we reported that ethanol induced a rapid reduction in BK message, including STREX, in hypothalamic neurons. While the absolute amount of mRNA for all BK $\alpha$ isoforms in hypothalamic neurons was reduced, the relative representation of STREX was enriched. Here, we show that over the course of hours, the absolute amount of STREX message in cultured striatal neurons is increased, in contrast to the results obtained in hypothalamic neurons. The most interesting explanation for this difference would be attributable to regional brain differences. Indeed, the actions of ethanol have been found to differ not only between neurons, but even between different subcellular compartments within a single neuron (Martin et al., 2004). 
The time-dependent transition to PMT described here may have important implications for the relationship between an individual's drinking pattern and development of tolerance, dependency, and addiction. While the relationship between events at the level of molecules and the level of complex behavior is difficult to pin down, recent studies have attempted to bridge this gulf by showing that $\mathrm{BK}$ subunit composition in genetically altered mice influences the response to alcohol at the levels of the single-channel protein, the action potential, and the behavioral response to the drug, including propensity to drink alcohol (Martin et al., 2008). Finally, we may question how such sophisticated responses to ethanol have arisen, and whether the evolutionary pressure was in response to ethanol in the environment, or whether ethanol has "hijacked" a mechanism designed to provide neural plasticity in response to other internal or external pressures.

\section{References}

Ahmed SH, Koob GF (1998) Transition from moderate to excessive drug intake: change in hedonic set point. Science 282:298-300.

Behrens R, Nolting A, Reimann F, Schwarz M, Waldschütz R, Pongs O (2000) hKCNMB3 and hKCNMB4, cloning and characterization of two members of the large-conductance calcium-activated potassium channel beta subunit family. FEBS Lett 474:99-106.

Ben-Shahar O, Moscarello JM, Ettenberg A (2006) One hour, but not 6 hours, of daily access to self-administered cocaine results in elevated levels of the dopamine transporter. Brain Res 1095:148-153.

Borlikova GG, Le Merrer J, Stephens DN (2006) Previous experience of ethanol withdrawal increases withdrawal-induced c-fos expression in limbic areas, but not withdrawal-induced anxiety and prevents withdrawal-induced elevations in plasma corticosterone. Psychopharmacology (Berl) 185:188-200.

Brewer GJ, Torricelli JR, Evege EK, Price PJ (1993) Optimized survival of hippocampal neurons in B27-supplemented Neurobasal, a new serumfree medium combination. J Neurosci Res 35:567-576.

Chen L, Tian L, MacDonald SH, McClafferty H, Hammond MS, Huibant JM, Ruth P, Knaus HG, Shipston MJ (2005) Functionally diverse complement of large conductance calcium- and voltage-activated potassium channel (BK) alpha-subunits generated from a single site of splicing. J Biol Chem 280:33599-33609.

Coe IR, Dohrman DP, Constantinescu A, Diamond I, Gordon AS (1996) Activation of cyclic AMP-dependent protein kinase reverses tolerance of a nucleoside transporter to ethanol. J Pharmacol Exp Ther 276:365-369.

Cowmeadow RB, Krishnan HR, Atkinson NS (2005) The slowpoke gene is necessary for rapid ethanol tolerance in Drosophila. Alcohol Clin Exp Res 29:1777-1786.

Cowmeadow RB, Krishnan HR, Ghezzi A, Al'Hasan YM, Wang YZ, Atkinson NS (2006) Ethanol tolerance caused by slowpoke induction in Drosophila. Alcohol Clin Exp Res 30:745-753.

Crabbe JC, Rigter H, Uijlen J, Strijbos C (1979) Rapid development of tolerance to the hypothermic effect of ethanol in mice. J Pharmacol Exp Ther 208:128-133.

Crippens D, White ML, George MA, Jaworski JN, Brunner LJ, Lancaster FE, Gonzales RA (1999) Gender differences in blood levels, but not brain levels, of ethanol in rats. Alcohol Clin Exp Res 23:414-420.

Dohrman DP, Chen HM, Gordon AS, Diamond I (2002) Ethanol-induced translocation of protein kinase A occurs in two phases: control by different molecular mechanisms. Alcohol Clin Exp Res 26:407-415.

Feinberg-Zadek PL, Treistman SN (2007) Beta-subunits are important modulators of the acute response to alcohol in human BK channels. Alcohol Clin Exp Res 31:737-744.

Ghezzi A, Al-Hasan YM, Larios LE, Bohm RA, Atkinson NS (2004) slo K(+) channel gene regulation mediates rapid drug tolerance. Proc Natl Acad Sci 101:17276-17281.

Hamill OP, Marty A, Neher E, Sakmann B, Sigworth FJ (1981) Improved patch-clamp techniques for high-resolution current recording from cells and cell-free membrane patches. Pflugers Arch 391:85-100.

Hanner M, Vianna-Jorge R, Kamassah A, Schmalhofer WA, Knaus HG, Kaczorowski GJ, Garcia ML (1998) The beta subunit of the high conduc- tance calcium-activated potassium channel. Identification of residues involved in charybdotoxin binding. J Biol Chem 273:16289-16296.

Hyman SE, Malenka RC, Nestler EJ (2006) Neural mechanisms of addiction: the role of reward-related learning and memory. Annu Rev Neurosci 29:565-598.

Jiang Z, Wallner M, Meera P, Toro L (1999) Human and rodent MaxiK channel beta-subunit genes: cloning and characterization. Genomics 55:57-67.

Kalant H (1998) Research on tolerance: what can we learn from history? Alcohol Clin Exp Res 22:67-76.

Kelz MB, Chen J, Carlezon WA Jr, Whisler K, Gilden L, Beckmann AM, Steffen C, Zhang YJ, Marotti L, Self DW, Tkatch T, Baranauskas G, Surmeier DJ, Neve RL, Duman RS, Picciotto MR, Nestler EJ (1999) Expression of the transcription factor $\delta$ FosB in the brain controls sensitivity to cocaine. Nature 401:272-276.

Khanna JM, Chau A, Shah G (1996) Characterization of the Phenomenon of rapid tolerance to ethanol. Alcohol 13:621-628.

Kittler JT, Chen G, Honing S, Bogdanov Y, McAinsh K, Arancibia-Carcamo IL, Jovanovic JN, Pangalos MN, Haucke V, Yan Z, Moss SJ (2005) Phospho-dependent binding of the clathrin AP2 adaptor complex to GABAA receptors regulates the efficacy of inhibitory synaptic transmission. Proc Natl Acad Sci U S A 102:14871-14876.

Krishnamoorthy G, Shi J, Sept D, Cui J (2005) The NH2 terminus of RCK1 domain regulates $\mathrm{Ca}^{2+}$-dependent $\mathrm{BK}(\mathrm{Ca})$ channel gating. J Gen Physiol 126:227-241.

Lê AD, Kalant H (1992) Influence of intoxicated practice on the development of acute tolerance to the motor impairment effect of ethanol. Psychopharmacology (Berl) 106:572-576.

Leveque JC, Macías W, Rajadhyaksha A, Carlson RR, Barczak A, Kang S, Li XM, Coyle JT, Huganir RL, Heckers S, Konradi C (2000) Intracellular modulation of NMDA receptor function by antipsychotic drugs. J Neurosci 20:4011-4020.

Lin HH, Chang SJ, Shie HJ, Lai CC (2006) Ethanol inhibition of NMDAinduced responses and acute tolerance to the inhibition in rat rostral ventrolateral medulla in vivo: involvement of cAMP-dependent protein kinases. Neuropharmacology 51:747-755.

Lippiat JD, Standen NB, Harrow ID, Phillips SC, Davies NW (2003) Properties of $\mathrm{BK}(\mathrm{Ca})$ channels formed by bicistronic expression of hSloalpha and beta1-4 subunits in HEK293 cells. J Membr Biol 192:141-148.

Martin G, Puig S, Pietrzykowski A, Zadek P, Emery P, Treistman S (2004) Somatic localization of a specific large-conductance calcium-activated potassium channel subtype controls compartmentalized ethanol sensitivity in the nucleus accumbens. J Neurosci 24:6563-6572.

Martin GE, Hendrickson LM, Penta KL, Friesen RM, Pietrzykowski AZ, Tapper AR, Treistman SN (2008) Identification of a BK channel auxiliary protein controlling molecular and behavioral tolerance to alcohol. Proc Natl Acad Sci U S A 105:17543-17548.

McManus OB (1991) Calcium-activated potassium channels: regulation by calcium. J Bioenerg Biomembr 23:537-560.

Meera P, Wallner M, Toro L (2000) A neuronal beta subunit (KCNMB4) makes the large conductance, voltage- and $\mathrm{Ca}^{2+}$-activated $\mathrm{K}+$ channel resistant to charybdotoxin and iberiotoxin. Proc Natl Acad Sci U S A 97:5562-5567.

Meredith GE, Agolia R, Arts MP, Groenewegen HJ, Zahm DS (1992) Morphological differences between projection neurons of the core and shell in the nucleus accumbens of the rat. Neuroscience 50:149-162.

Nestler EJ, Barrot M, Self DW (2001) Delta FosB: A sustained molecular switch for addiction. Proc Natl Acad Sci U S A 98:11042-11046.

Pandey SC, Roy A, Mittal N (2001) Effects of chronic ethanol intake and its withdrawal on the expression and phosphorylation of the creb gene transcription factor in rat cortex. J Pharmacol Exp Ther 296:857-868.

Pandey SC, Roy A, Zhang H (2003) The decreased phosphorylation of cyclic adenosine monophosphate (cAMP) response element binding (CREB) protein in the central amygdala acts as a molecular substrate for anxiety related to ethanol withdrawal in rats. Alcohol Clin Exp Res 27:396-409.

Petrik D, Brenner R (2007) Regulation of STREX exon large conductance, calcium-activated potassium channels by the beta4 accessory subunit. Neuroscience 149:789-803.

Pietrzykowski AZ, Martin GE, Puig SI, Knott TK, Lemos JR, Treistman SN (2004) Alcohol tolerance in large-conductance, calcium-activated potassium channels of CNS terminals is intrinsic and includes two compo- 
nents: decreased ethanol potentiation and decreased channel density. J Neurosci 24:8322-8332.

Pietrzykowski AZ, Friesen RM, Martin GE, Puig SI, Nowak CL, Wynne PM, Siegelmann HT, Treistman SN (2008) Posttranscriptional regulation of BK channel splice variant stability by miR-9 underlies neuroadaptation to alcohol. Neuron 59:274-287.

Renthal W, Carle TL, Maze I, Covington, HE 3rd, Truong HT, Alibhai I, Kumar A, Montgomery RL, Olson EN, Nestler EJ (2008) Delta FosB mediates epigenetic desensitization of the c-fos gene after chronic amphetamine exposure. J Neurosci 28:7344-7349.

Scholz H, Ramond J, Singh CM, Heberlein U (2000) Functional ethanol tolerance in Drosophila. Neuron 28:261-271.

Schuckit MA (1994) Low level of response to alcohol as a predictor of future alcoholism. Am J Psychiatry 151:184-189.

Treistman SN, Martin GE (2009) BK Channels: mediators and models for alcohol tolerance. Trends Neurosci 32:629-637.

Vergara C, Latorre R, Marrion NV, Adelman JP (1998) Calcium-activated potassium channels. Curr Opin Neurobiol 8:321-329.
Vergara C, Alvarez O, Latorre R (1999) Localization of the $\mathrm{K}^{+}$lock-In and the $\mathrm{Ba}^{2+}$ binding sites in a voltage-gated calcium-modulated channel. Implications for survival of K+ permeability. J Gen Physiol 114:365-376.

Wang Y, Krishnan HR, Ghezzi A, Yin JC, Atkinson NS (2007) Druginduced epigenetic changes produce drug tolerance. PLoS Biol 5:e265.

Wang Y, Ghezzi A, Yin JC, Atkinson NS (2009) CREB regulation of BK channel gene expression underlies rapid drug tolerance. Genes Brain Behav 8:369-376.

Wang X, Dayanithi G, Lemos JR, Nordmann JJ, Treistman SN (1991) Calcium currents and peptide release from neurohypophysial terminals are inhibited by ethanol. J Pharmacol Exp Ther 259:705 711.

Xia XM, Zeng X, Lingle CJ (2002) Multiple regulatory sites in largeconductance calcium-activated potassium channels. Nature 418:880-884.

Xie J, McCobb DP (1998) Control of alternative splicing of potassium channels by stress hormones. Science 280:443-446.

Yuan C, O'Connell RJ, Wilson A, Pietrzykowski AZ, Treistman SN (2008) Acute alcohol tolerance is intrinsic to the BKCa protein, but is modulated by the lipid environment. J Biol Chem 283:5090-5098. 